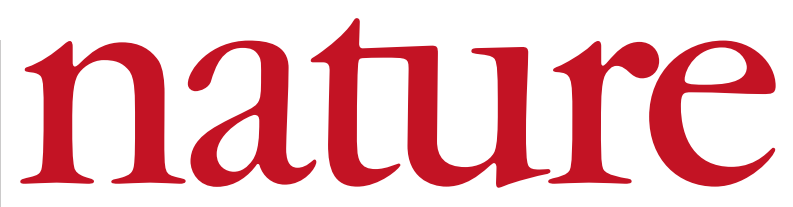

1 July 2004 Volume 430 Issue no 6995

\title{
Conflicts at the NIH (cont.)
}

Previous assurances by the director of the US National Institutes of Health to Congress over the regulation of conflicts of interest are contradicted by fresh allegations. Tough new rules for staff seem essential to restore public confidence.

L ast week, an ongoing investigation into conflicts of interest at the National Institutes of Health (NIH) took a new and more serious turn. Congressional investigators claimed that the NIH had seriously underestimated the number of consulting agreements that its scientists held with outside entities. After contacting pharmaceutical companies, the investigators claimed to have found about 100 instances in which NIH scientists had consulted with industrial partners without notifying the agency.

The investigations subcommittee of the House Committee on Energy and Commerce has yet to look into all these cases, but a few examples cited at the hearing seem to undermine what NIH director Elias Zerhouni has previously stated: that NIH employees have always rigorously adhered to ethics rules. Now it seems that, at least in some cases, NIH employees circumvented the regulations that require them to ask for approval for their paid consulting activities. The committee is alleging that there is more than just smoke there is fire too.

As yet there has been no response from the employees who have been singled out in the congressional hearing. They face several specific accusations, including misleading the committee in previous testimony over the extent of consultancies with biotechnology companies. The NIH says that some of the discrepancies between its own accounting and that of the committee are due to mistakes in its own paperwork, rather than wrong-doing by its employees. It also says that, in some cases, discrepancies occurred because the NIH tallied consulting arrangements differently from the pharmaceutical companies.

Zerhouni has now told the subcommittee — chaired by James Greenwood (Republican, Pennsylvania) — that "drastic changes" must occur at the NIH. He has proposed a ban on paid consulting work by senior NIH officials. Less senior employees could still consult, but would only be able to receive the equivalent of $25 \%$ of their salaries in consulting payments, and must limit their consulting time to 400 hours. No NIH employee would be allowed to accept stocks as payments. And many scientists would be prevented from holding any stock at all in a drug or biotechnology company.

Some of these and other proposed changes go far beyond those recommended by a specially commissioned panel that issued its report in May. And many NIH scientists are disturbed by them. Some have vowed to leave the agency if the changes require them, for instance, to sell long-held stocks in drug companies. But if the problems are as significant as they appear, the NIH must make some sacrifices now if it is to restore its reputation.

The rules on consultancies were loosened in 1995 under its director at the time, Harold Varmus. Shortly afterwards, the NIH benefited from a lobbying campaign that resulted in a doubling of its budget between 1998 and 2003. The new allegations raise questions about whether the NIH's leaders during that time - Varmus followed by acting director Ruth Kirschstein, who led the agency from 2000 to early 2002 — did all that they could to ensure that their house was in order, when a funding boom was bound to bring closer scrutiny.

Congress being what it is, there is more than a whiff of political opportunism in the handling of these allegations. But long-standing advocates on behalf of the NIH say that the conflict-of-interest scandal has crippled their ability to lobby for funds. Zerhouni's proposed restrictions on his colleagues may be drastic, but they may also be exactly what the NIH needs if it is to regain its status as the crown jewel of the federal government.

\section{Risks of high winds}

\section{Proponents of turbines on top of New York's Freedom Tower had better get their sums right.}

O $f$ all the possible sources of renewable energy, wind farms have provoked some of the strongest resistance. Objectors point to a variety of concerns, from the risk posed to migratory birds to the chance that the spinning blades could fling ice in all directions during winter. But most of all, it seems, people just don't want the towering turbines to spoil the views from their back gardens.

So proponents of wind power were thrilled to learn in December that the current design for what is to be the world's tallest building to be erected at the site of the terrorist attacks on 11 September 2001 in New York - calls for a massive wind farm in its upper storeys. When completed, the Freedom Tower and its turbines will be visible to millions (see page 12).

Provided, that is, that the wind turbines are ever installed. They were the brainchild of the architects Skidmore, Owings \& Merrill. But people who build wind turbines for a living say they doubt whether the architects consulted wind engineers before floating the proposal. They say the structural challenges involved in damping vibrations and noise are too great to be cost-effective. One told Nature he thought the proposal was a joke. Another said he didn't believe that the turbines would ever be built. Skidmore, Owings \& Merrill declined Nature's request for a response to the criticism.

Nevertheless, several optimistic companies have submitted proposals. One says it can make the job cost-effective with a turbine that spins on a vertical axis, rather than the usual propeller-like blades that spin on a horizontal axis. This would be good news, but the fact remains that vertical-turbine technology lags far behind and has not yet been used in any successful commercial installation.

Much more is at stake here than just an engineering dispute over what is possible. The amount of electricity involved is small compared with New York's voracious appetite, but the symbolism is huge. Wind power, whether urban or rural, could help ease us into our inevitable oil-free future. Yet a failure on the scale and visibility of the Freedom Tower could dampen enthusiasm for this much-needed renewable resource far more than a few dead birds could. Let's hope the optimists have it right. 